\title{
REFLEXIONES SOBRE EL PASADO Y EL PRESENTE EN EL CONTEXTO LATINOAMERICANO: MIRADAS DESDE LA HISTORIA Y LAS CIENCIAS SOCIALES
}

\author{
REFLECTIONS ON THE PAST AND PRESENT IN THE LATIN AMERICAN \\ CONTEXT: VIEWS FROM HISTORY AND THE SOCIAL SCIENCES
}

\author{
Karelia Cerda Castro*
}

Diálogo Andino, Revista de Historia, Geografía y Cultura Andina, difunde a través de sus páginas investigaciones científicas inéditas, con la finalidad de contribuir a la construcción de conocimiento respecto de las sociedades latinoamericanas y, especialmente, del contexto Sur Andino. Esta edición incorpora diversas temáticas de interés, tales como el patrimonio, los estudios pedagógicos, análisis sobre ciudadanía, migración y política exterior, entre otros, a partir de variados enfoques y disciplinas de las Ciencias Sociales y las Humanidades.

Los primeros tres artículos, abordan temáticas vinculadas a pueblos originarios e interculturalidad en distintos contextos. El primer artículo de este número, escrito por Alejandra Lazo, Hernan Riquelme y Viviana Huiliñir, presenta un análisis de la movilidad cotidiana en sectores rurales de población principalmente mapuche-williche, en donde se despliegan prácticas y dinámicas socioculturales particulares en relación a migraciones internas entre lo rural y lo urbano, este manuscrito constituye un relevante aporte al estudio de este fenómeno histórico que había carecido de atención por parte de la investigación académica. En segundo lugar, el investigador Álvaro Espinoza aborda la problemática del cumplimiento de estándares jurídicos internacionales por parte del Estado chileno, en relación con el derecho a la identidad cultural de la infancia aymara, mediante un análisis de casos en el norte de Chile, esta temática reviste gran importancia para nuestra región dado que problematiza desde las ciencias jurídicas una realidad latente, abordándola desde una perspectiva comparada con el Derecho internacional. Por su parte, la investigación de Alejandra Carreño y Andrea Freddi analiza las formas de participación de poblaciones aymaras en los programas de salud intercultural -implementados en Chile por los gobiernos desde la transición democrática- mediante la "performatividad" como práctica democrática, en relación a la salud y la enfermedad, evidenciando cómo el Estado chileno ha utilizado dichos programas como dispositivos de control sobre los cuerpos de los pueblos originarios, no obstante éstos han desplegado formas de participación democrática desde sus saberes; resulta interesante la propuesta de estas autoras, pues complejizan las nociones de inclusión mediante el control social en materia de salud e interculturalidad.

Posteriormente, se presentan tres interesantes artículos que trabajan la participación ciudadana en contextos latinoamericanos. Kepler Ribadeneira indaga en la noción del Buen Vivir -Sumak kawsay- como paradigma latinoamericano de convivencia armónica -a partir de los aportes de la realidad multicultural del Ecuador-, dicho concepto está instalado en la Constitución ecuatoriana pero, sin embargo, en la práctica las políticas públicas para su materialización han sido deficientes, la propuesta del autor apunta no sólo al plano gubernamental, sino también al debate intelectual respecto del Buen Vivir como categoría epistémica alternativa, desde América Latina, al modelo económico imperante. En una dirección similar, el artículo titulado "No aman discutir con la gente. Paradojas de la participación ciudadana en Ibambura, Ecuador (2008-2017)" -de los autores Miquel Fernández y Jorge Torres- analiza las formas en que la Constitución ecuatoriana consagró la participación ciudadana en el funcionamiento gubernamental y la toma de decisiones políticas, no obstante plantea críticamente y en

\footnotetext{
* Universidad de Tarapacá. Departamento de Ciencias Históricas y Geográficas.

Correo electrónico: kcerdac@académicos.uta.cl
} 
base a un estudio cualitativo que, en la práctica, esta premisa no se ve reflejada, puesto que existe una tendencia a la institucionalización y control de la participación ciudadana en las zonas urbanas de la provincia andina de Ibambura, junto con señalar que inclusive en localidades rurales esta problemática se agudiza en tanto que las limitaciones a la participación son mayores. Finalmente, Ángel Barbas y Ana Martínez Ortiz de Zárate abordan la participación ciudadana activa a través de medios de comunicación comunitarios, los cuales son identificados como importantes fuentes educativas para la ciudadanía, además de tener un impacto en la trayectoria personal de quienes participan de éstos -en los planos emocional y cognitivo-. Estos artículos contribuyen a replantear las relaciones entre los Estados y la sociedad civil, especialmente en un contexto de surgimiento y auge de importantes movimientos sociales, relevando las posibilidades analíticas multidisciplinares en la búsqueda de alternativas democráticas en las sociedades latinoamericanas.

Posteriormente, el texto "Trayectorias personales de los emprendimientos laborales de inmigrantes chilenos en Almería, España" analiza el fenómeno de la migración a partir de las motivaciones y formas que adquieren los emprendimientos personales de migrantes chilenos en España, desde dimensiones económicas como también sociales, este artículo enriquece el conocimiento en torno a la calidad de vida de las y los migrantes chilenos en Europa. El investigador Máximo Quitral, expone las formas en que la dictadura cívico-militar en Paraguay, además de características internas propias de dicho país, configuraron las prácticas sus diplomáticas actuales, lo cual nos invita a la reflexión en torno a otros contextos postdictatoriales -especialmente en el Cono Sur-y las políticas exteriores.

Los autores Nilson Ibagón y Daniel Parodi, presentan cada uno investigaciones relacionadas con la enseñanza de la Historia en la etapa escolar, el primero aborda la construcción de un relato oficial acrítico de dos procesos de gran relevancia en la construcción sociopolítica del Estado-nación en Colombia; mientras que el segundo analiza cómo se plasman determinadas ideas -el nacionalismo, liberalismo y republicanismo- a través de los textos escolares de educación Básica, lo cual de igual forma tiene un impacto en la configuración de la noción histórica de la nación extendida entre la ciudadanía a partir del estudio del periodo de las Cortes de Cádiz. Por otra parte, Ángel Heredia indaga en la construcción de la figura mitificada de José Carlos Mariátegui entre la izquierda peruana, a partir de su vinculación con elementos culturales propios -vinculados al componente indígena-, los cuales dotaron de determinadas características su figura, difundida especialmente a través de textos de formación política de Sendero Luminoso. En estos tres artículos se evidencia el rol que cumple la educación -ya sea la enseñanza escolar o las instancias de formación política- en la configuración ideológica de la ciudadanía respecto de la historia nacional.

En una dirección distinta, desde el enfoque de la Educación, en el texto "Patrimonio local en el aula. Una mirada desde escolares a lugares emblemáticos de la región de Antofagasta" se indaga en la asociación y representación del entorno por parte de escolares, desde donde se analiza el arraigo y sentido de pertenencia al territorio en que residen. Finalmente, el investigador Lucas Maubert aporta una interesante mirada al impacto de la Primera Guerra Mundial en el contexto regional de Arica y Tacna, a través del estudio de la prensa y los abordajes del conflicto internacional, los cuales generaron un impacto en la opinión pública de ambas localidades.

En contextos de alta convulsión social, política y económica, el aporte de la investigación científica adquiere central importancia para replantear tanto el pasado como el presente, complejizar y problematizar los procesos históricos pasados y los fenómenos contemporáneos que marcan el desarrollo de nuestras sociedades. Esperamos que esta edición de Revista Diálogo Andino constituya un aporte en esa dirección. 